hoặc mạch máu hoặc mạch bách huyết. Trước đây bệnh nhân ung thư vú, hạch nách âm tính được coi là tiên lượng tốt. Những nghiên cứu sau này cho thấy môt số bênh nhân ung thư vú có hach nách âm tính vẫn có tái phát và tử vong sớm nếu không được điều trị bổ trợ [1]. Theo Weigand (1992) cho thây những bệnh nhân có xâm nhập mạch máu và di căn hạch thì $70 \%$ tái phát sau hai năm, trong đó các trường hợp khác chỉ có $15 \%[5]$.

\section{KẾT LUÂN}

UTBM tuyến vú có di căn hạch nách và xâm nhập mạch máu cao hơn nhóm UTBM tuyến vú khổng di căn hạch nhưng có xâm nhập mạch máu (79,2\% so với $20,8 \%)$. Tương tự, UTBM tuyến vú có di căn hạch và xâm nhập bạch mạch cao hơn nhóm UTBM tuyến vú không di căn hạch nhưng có xâm nhập bạch (74,3\% so với $25,7 \%)$. Tỷ lệ di căn số lượng hạch càng nhiều thì tỷ lệ xâm nhập mạch máu và bạch mạch càng cao.

\section{TÀI LIẸU THAM KHẢO}

1. McGuire WL và Clark GM326 (1992), Prognostic factors and treatment decisions in axillary node negative breast cancer, $\mathrm{N}$ Engl J Med,
1756-61

2. Bettelheim R, Penman HG (1984). Prognostic significance of peritumoral vascular invasion in breast cancer, $\mathrm{Br}$ J Cancer, 50,771-77.

3. Ta văn Tờ (2004), Nghiên cứu hình thái học hóa mô miễn dịch và giá trị tiên lượng của chúng trong ung thư biểu mô tuyến vú, Luận án tiến sỹ y học, Trường đai hoc $Y$ Hà Nôi.

4. Saigo PE, Braun DW, et al (1981), Predictors of recurrence in stage I (T1NOM0) breast carcinoma, Ann surg, 193, 15-25.

5. Weigand RA, Isenberg WM, Russo J et al (1992). Blood vessel invasion and axillary lymph node invovement as prognostic indicator for human breast cancer, Cancer, 50(5), 962-9.

6. Đặng Công Thuân (2007), Ứng dụng chỉ số Nottingham và một số yếu tố khác trong phân nhóm tiên lượng ung thư biểu mô tuyến vú xâm nhập, Luận án Tiến sỹ, Trường Đại học Y Hà Nội.

7. Kahn HJ và Marks A (2002). A new monoclonal antibody, D2-40, for detection of lymphatic invasion in primary tumors, $1255-1257$.

8. Truong $T$. Pauline, Lee $J$ at al (2005). Locoregional recurren risks in elderly breast cancer patient treated with mastectomy without adjuvant radiotherapy, Eur ] Cancer,41, 1267-1277.

9. Filho, H.R.O, Dória M.T et al (2015). Criteria for prediction of metastatic axillary lymph nodes in early-stage breast cancer. Rev Bras Ginecol Obstet, 37(7):308-13.

\title{
ĐÁNH GIÁ MộT Số TÁC DỤNG KHÔNG MONG MUỐN CỦA PHÁC Đồ EOX TRONG ĐIÊUU TRI UNG THƯ DẠ DÀY Ở NGƯỜI CAO TUỔI
}

\section{TÓM TẮT}

Mục tiêu: Đánh giá tác dụng không mong muốn của phác đồ EOX trong điều trị ung thư da dày ở người cao tuổi sau phâuu thuật triệt căn. Phương pháp nghiên cứu: Nghiên cứu can thiệp lâm sàng không đối chứng có theo dõi dọc, kết hợp tiến cứu và hồi cứu. Gồm 57 bệnh nhân là người cao tuổi được chẩn đoán xác định là ung thư dạ dày giai đoạn IIaIIIc được điều trị phẫu thuật tai bệnh viện $\mathrm{K}$ và bệnh viện $E$ từ tháng 1/2009 đến tháng 12/2019. Kết quả: Độ tuổi trung bình trong nghiên cứu là $63,7 \pm 3,4$, với tỉ lệ nam/nữ là 3/1. Bệnh kèm theo là tăng huyết áp $(15,8 \%)$, viêm loét dạ dày $(12,3 \%)$, bệnh thận hoặc đường tiết niệu $(12,3 \%)$, đái tháo đường (10,5\%). Tác dung không mong muốn chung trên huyết hoc chủ yểu ở độ 1 , trong đó có $1,5 \%$ hạ bạch câu, $2,6 \%$ hạ bạch câu hạt độ 3-4 và $0,4 \%$ hạ tiểu cầu độ 4 ; Tác dụng không mong muốn chung trên chức nẳng gan

${ }^{1}$ Bệnh viện $E$

Chịu trách nhiệm chính: Lê Thành Trung

Email: bslethanhtrung@yahoo.com

Ngày nhận bài: 4.3.2021

Ngày phản biên khoa học: 29.4.2021

Ngày duyệt bài: 13.5.2021

\section{Lê Thành Trung ${ }^{1}$, Đoàn Hữu Nghị ${ }^{1}$}

thận chủ yếu ở độ $1-2$, trong đó cao nhất là tăng SGOT $(29,3 \%)$ và SGPT $(20,2 \%)$; Tác dung không mong muốn chung trên lâm sàng chủ yểu ở độ 1 , nhưng có 3,2\% số đợt nôn mức đô 3- 4, 1,5\% tiêu chảy mức độ 3-4, 2,6\% bệnh nhân chán ăn mức độ 34 và có 05 bệnh nhân dung nạp kém phải chuyển phác đồ Xelox. Kết luận: Hóa trị bổ trợ phác đồ EOX là môt lưa chọn cho các bênh nhân người cao tuổi UTDD đã được phẫu thuật triệt căn có nguy cơ cao.

Tư khóa: Ung thư dạ dày; phác đồ EOX; tác dụng không mong muốn, người cao tuổi.

\section{SUMMARY \\ EVALUATION ON THE SIDE EFFECTS OF EOX REGIMEN IN TREATING GASTRIC CANCER IN ELDERLY PATIENTS}

Objectives: to evaluate the side effects of EOX regimen of treating gastric cancer in elderly patients after radical surgery. Subjects and methods: Noncontrolled clinical interventional study with vertical follow-up, with a combination of prospective and retrospective study was conducted on 57 elderly patients diagnosed with gastric cancer staged IIa IIIc and undergoing surgical treatment at $\mathrm{K}$ Hospital and E hospital from January, 2009 to December, 2019. Results: The mean age of the subjects in the 
study was $63.7 \pm 3.4$ years old, with a male/female ratio of $3 / 1$. Pre-existing diseases were hypertension $(15.8 \%)$, gastric ulcers $(12.3 \%)$, kidney or urinary tract diseases $(12.3 \%)$, diabetes $(10.5 \%)$. The overall side effects on hematology was mainly at grade 1 , including $1.5 \%$ leukopenia, $2.6 \%$ grade $3-4$ agranulocytosis and $0.4 \%$ grade 4 thrombocytopenia ; The overall side effects on liver and kidney function was mainly at grade 1 , of which the highest was the increase in SGOT (29.3\%) and SGPT (20.2\%); The overall clinical side effects was mainly at grade 1 , but there were $3.2 \%$ episodes of vomiting grade $3-4$, $1.5 \%$ diarrhea grade $3-4,2.6 \%$ anorexia grade $3-4$ and 05 patients with poor tolerance who had to change to Xelox regimen instead. Conclusions: Adjuvant chemotherapy EOX is an option for high-risk gastric cancer patients with radical surgery.

Keywords: gatric cancer, EOX regimen, side effects, elderly.

\section{I. ĐĂT VẤN ĐỀ}

Ung thư da dày (UTDD) là một trong những bệnh ung thư phổ biến nhất trên thế giới. Năm 2018, ước tính trên thế giới có 1.033 .700 trường hợp ung thư da dày mắc mới và hơn 782.600 trường hợp tử vong. Tại Việt nam theo Globocan 2018, UTDD đứng thứ 3 ở cả hai giới sau ung thư gan và ung thư phổi với tỷ lệ mắc chuẩn theo tuổi là 11,38/100.000 dân. Trong đó, loại ung thư biểu mô tuyến chiếm chủ yếu (90-95\%) [1].

Trong điều trị ung thư da dày, phẫu thuâat được xem là phương pháp điều trị chính. Các nghiên cứu ở nước ta cho thấy đa số bệnh nhân được chẩn đoán ở giai đoạn bệnh tiến triển, thường xuất hiện tái phát, di cằn sau khi đã được phẫu thuật [2],[3]. Mặc dù kỹ thuật phẫu thuật ung thư da dày ngày càng tiến bộ, nhưng kết quả sống thềm toàn bộ của bệnh nhân ung thư dạ dày giai đoạn tiến triển vẫn thấp. Chính vì vậy, để cải thiện tiên lượng của ung thư dạ dày giai đoạn tiến triển, ngoài hoàn thiện phương pháp phẫu thuật điều trị triệt căn cổ điển, hiện nay các nghiên cứu tập trung điều trị đa mô thức như phẫu thuật kết hợp hóa chất, hóa-xạ phối hợp, miễn dịch-sinh học... đặc biệt phương pháp điều trị hóa trị toàn thân là rất cần thiết.

ở Việt Nam và trên thế giới đã có một số nghiên cứu đánh giá kết quả điêu trị và tác dụng không mong muốn của phác đồ EOX trong điều trị ung thư dạ dày sau phẫu thuật triệt căn, tuy nhiên chưa có nhiêu nghiên cứu thực hiện trên đối tượng là người cao tuổi, với nhiều bệnh lý kèm theo. Vì vậy, chúng tôi tiến hành nghiển cứu này với mục đích: Đánh giá tác dụng không mong muốn của phác đồ EOX trong điều trị ung thư dạ dày ở người cao tuổi sau phẫu thuật triệt căn.

\section{II. ĐỐI TƯỢNG VÀ PHƯƠNG PHÁP NGHIÊN CứU}

Nghiên cứu can thiệp lâm sàng không đối chứng có theo dõi dọc, kết hợp tiến cứu và hồi cứu.

Đối tượng nghiên cứu. Từ tháng 1/2009 đến tháng 12/2019, chúng tôi tiến hành nghiên cứu trên 57 bệnh nhân (là người cao tuổi: từ 60 tuổi trở lên theo định nghĩa của WHO và Pháp lệnh về người cao tuổi của ủy ban thường vụ quốc hội nước $\mathrm{CHXHCN}$ Việt Nam, Số 23/2000/PL-UBTVQH10 ngày 28/4/2000) được chẩn đoán xác định là ung thư da dày giai đoạn IIa-IIIc được điều trị phẫu thuật tại Bệnh viện $\mathrm{K}$ và bệnh viện $E$.

Tiêu chuẩn lựa chọn: Bệnh nhân được chẩn đoán xác định là ung thư dạ dày giai đoạn IIa-IIIc. Mô bệnh học loai ung thư biểu mô; Tuổi $\geq 60$; Được điêu trị phẩu thuật cắt dạ dày triệt căn; Được điêu trị hóa chất phác đồ EOX; Hồ sơ lưu trữ đầy đủ; Đồng ý tham gia nghiên cứu

Tiêu chuẩn loaii trừ: Thể trạng yếu; Đã được hóa xạ trị trước mổ hoặc phẫu thuật không đảm bảo triệt căn; Các trường hợp đã mắc một bệnh ung thư khác

Tiến hành nghiên cứu: những bệnh nhân có đủ các tiêu chuẩn sẽ được chọn vào nghiên cứu. Thông tin của các bệnh nhẩn nghiên cứu được thu thập và ghi nhận theo mẫu bệnh án nghiên cứu.

Phác đồ EOX: -Epirubicin: $50 \mathrm{mg} / \mathrm{m} 2 \mathrm{da}$, truyền tĩnh mạch ngày 1

- Oxaliplatin: $130 \mathrm{mg} / \mathrm{m} 2 \mathrm{da}$, truyền tĩnh mạch ngày 1

- Xeloda (Capecitabine): 625 mg/m2 da, uống

2 lần/ngày từ ngày $1-21$

Chu kỳ 21 ngày x 6 chu kỳ.

Đánh giá tác dụng không mong muốn của phác đồ hóa chất dựa vào tiêu chuẩn phân độ độc tính thuốc chống ung thư của Tổ chức $Y$ tế thế giới.

\section{KẾT QUẢ NGHIÊN CỨU Thông tin chung}

Bảng 2.1. Đặc điểm tuổi giới của nhóm nghiên cứu ( $n=57)$

\begin{tabular}{|c|c|c|c|c|c|}
\hline \multirow{2}{*}{ Nhóm tuổi $\quad$ Giới tính } & \multicolumn{2}{|c|}{ Nam } & \multicolumn{2}{|c|}{$\mathbf{N} \tilde{u}$} & \multirow{2}{*}{$\mathbf{P}$} \\
\hline & $\mathbf{n}$ & $\%$ & $\mathbf{n}$ & $\%$ & \\
\hline$\leq 65$ & 33 & 76,7 & 11 & 78,6 & \\
\hline$>65$ & 10 & 22,3 & 3 & 21,4 & \\
\hline
\end{tabular}




\begin{tabular}{|c|c|c|c|c|c|}
\hline Tống & 43 & 75,4 & 14 & 24,6 & \\
\hline Tuối trung bình & $63,7 \pm 3,1(60-72)$ & $62,8 \pm 2,8(60-69)$ & $63,7 \pm 3,4(60-72)$ \\
\hline
\end{tabular}

Nhận xét: Đa số bệnh nhân trong nghiên cứu là nam chiếm tỉ lệ $75,4 \%$, nữ là $24,6 \%$, tỉ lệ xấp xỉ $3 / 1$. Tuổi trung bình của nam là $63,7 \pm 3,1$ tuổi, của nữ là $62,8 \pm 2,8$, trung bình chung của nghiên cứu là $63,7 \pm 3,4$.

Bảng 2.2 Bệnh kèm theo của nhóm nghiên cứu (n=57)

\begin{tabular}{|c|c|c|c|}
\hline \multicolumn{2}{|c|}{ Bệnh kèm theo } & Số lượng (n=57) & Tỉ lệ \% \\
\hline \multirow{2}{*}{ Tim mạch } & Tăng huyết áp & 9 & 15,8 \\
\cline { 2 - 4 } & Block nhĩ thất & 2 & 3,6 \\
\hline \multirow{2}{*}{ Cơ xương khớp } & Viêm khớp, thấp khớp & 4 & 7,0 \\
\cline { 2 - 4 } & Đau lưng mãn tính & 5 & 8,8 \\
\hline \multirow{2}{*}{ Bệnh thận hoặc đường tiết niệu } & 7 & 12,3 \\
\hline \multirow{3}{*}{ Khác } & Đái tháo đường & 6 & 10,5 \\
\cline { 2 - 4 } & Viêm gan B & 1 & 1,8 \\
\cline { 2 - 4 } & Xuất huyết tiêu hóa & 1 & 1,8 \\
\cline { 2 - 4 } & Viêm loét dạ dày & 7 & 12,3 \\
\hline
\end{tabular}

Nhận xét: Bệnh nhân chủ yếu có bệnh kèm theo là tăng huyết áp (15,8\%), viêm loét dạ dày (12,3\%), bệnh thận hoặc đường tiết niệu (12,3\%), đái tháo đường (10,5\%).

Kết quả điều trị hóa chất sau mổ

Bảng 2.4. Liều thuốc trong điều trị $(n=57)$

\begin{tabular}{|c|c|c|c|c|c|c|}
\hline \multirow{2}{*}{ Liêuu hóa chất } & \multicolumn{2}{|c|}{$\mathbf{8 5 \%} \% \mathbf{1 0 0}$} & \multicolumn{2}{|c|}{$\mathbf{1 0 0} \%$} & \multicolumn{2}{c|}{ Tống số } \\
\cline { 2 - 6 } & $\mathbf{n}$ & $\mathbf{\%}$ & $\mathbf{n}$ & $\mathbf{\%}$ & $\mathbf{n}$ & $\mathbf{\%}$ \\
\hline Chu kỳ 1 & 46 & 80,7 & 11 & 19,3 & 57 & 100 \\
\hline Chu kỳ 2 & 46 & 80,7 & 11 & 19,3 & 57 & 100 \\
\hline Chu kỳ 3 & 44 & 77,2 & 13 & 22,8 & 57 & 100 \\
\hline Chu kỳ 4 & 39 & 68,4 & 18 & 31,6 & 57 & 100 \\
\hline Chu kỳ 5 & 35 & 61,4 & 22 & 38,6 & 57 & 100 \\
\hline Chu kỳ 6 & 34 & 59,6 & 23 & 40,4 & 57 & 100 \\
\hline Tống số & 244 & 71,3 & 98 & 28,7 & 342 & 100 \\
\hline
\end{tabular}

Nhân xét: Tất cả bênh nhân được điều trị với liều trên $85 \%$ tống liều, trong đó có $28,7 \%$ số chu kỳ bệnh nhân được dùng đủ 100\% liều .

Bảng 2.5. Độc tính chung trên huyêt học qua 6 chu ky่ (n=57)

\begin{tabular}{|c|c|c|c|c|c|c|c|c|}
\hline \multirow{2}{*}{ Các chỉ số } & \multicolumn{2}{|c|}{ Độ 1 } & \multicolumn{2}{c|}{ Độ 2 } & \multicolumn{2}{c|}{ Độ 3-4 } & \multicolumn{2}{c|}{ Tống số } \\
\cline { 2 - 9 } & $\mathbf{n}$ & $\mathbf{\%}$ & $\mathbf{n}$ & $\mathbf{\%}$ & $\mathbf{n}$ & $\mathbf{\%}$ & $\mathbf{n}$ & $\mathbf{\%}$ \\
\hline Huyết sắc tố & 99 & 28,9 & 33 & 9,6 & 0 & 0 & 132 & 38,5 \\
\hline Bạch câu & 26 & 7,6 & 7 & 2 & 5 & 1,5 & 38 & 11,1 \\
\hline BC hạt & 54 & 15,8 & 34 & 9,9 & 9 & 2,6 & 97 & 28,3 \\
\hline Tiếu cầu & 39 & 11,4 & 2 & 0,6 & 1 & 0,4 & 42 & 12,4 \\
\hline
\end{tabular}

Nhận xét: Hâuu hết bệnh nhân gặp độc tính chung trên huyết học độ 1. Trong đó có 2,6\% số đợt hạ bạch cầu hạt độ 3-4, có 5 chu kỳ hạ bạch câu độ 3-4 và 01 chu kỳ hạ tiểu câu độ 4.

\section{Bảng 2.6. Độc tính chung trên chức năng gan - thận qua 6 chu kỳ $(n=57)$}

\begin{tabular}{|c|c|c|c|c|c|c|c|c|}
\hline \multirow[b]{2}{*}{ Các chỉ số } & \multicolumn{2}{|c|}{ Đô̂ 1} & \multicolumn{2}{|c|}{ Đố 2} & \multicolumn{2}{|c|}{ Đô 3-4 } & \multicolumn{2}{|c|}{ Tổng số } \\
\hline & $\mathbf{n}$ & $\%$ & $\mathbf{n}$ & $\%$ & $\mathbf{n}$ & $\%$ & $\mathbf{n}$ & $\%$ \\
\hline SGOT & 98 & 28,7 & 2 & 0,6 & 0 & 0 & 100 & 29,3 \\
\hline SGPT & 65 & 19 & 4 & 1,2 & 0 & 0 & 69 & 20,2 \\
\hline Creatinine & 20 & 5,8 & 0 & 0 & 0 & 0 & 20 & 5,8 \\
\hline Ure & 13 & 3,8 & 0 & 0 & 0 & 0 & 13 & 3,8 \\
\hline
\end{tabular}

Nhận xét: Hầu hết bệnh nhân gặp độc tính chung trên chức năng gan-thận độ 1-2 với SGOT $29,3 \%$, SGPT 20,2\%, creatinin 5,8\%, ure 3,8\%.

Bảng 2.7. Các tác dụng phụ trên lâm sàng chung qua 6 chu kỳ $(n=57)$

\begin{tabular}{|c|c|c|c|c|c|c|c|c|}
\hline \multirow{2}{*}{ Đăc điểm } & \multicolumn{2}{|c|}{ Đô 1} & \multicolumn{2}{|c|}{ Độ 2} & \multicolumn{2}{|c|}{ Đô 3-4 } & \multicolumn{2}{|c|}{ Tổng số } \\
\hline & $\mathbf{n}$ & $\%$ & $\mathbf{n}$ & $\%$ & $\mathbf{N}$ & $\%$ & $\mathbf{n}$ & $\%$ \\
\hline Chán ăn & 131 & 38,3 & 12 & 3,5 & 9 & 2,6 & 152 & 44,4 \\
\hline Buồn nôn, nôn & 116 & 33,9 & 10 & 2,9 & 11 & 3,2 & 137 & 40,0 \\
\hline
\end{tabular}


VIETNAM MEDICAL JOURNAL N02 - MAY - 2021

\begin{tabular}{|c|c|c|c|c|c|c|c|c|}
\hline Tiêu chảy & 47 & 13,7 & 8 & 2,3 & 5 & 1,5 & 60 & 17,5 \\
\hline Hội chứng bàn tay - Chân & 40 & 11,7 & 12 & 3,5 & 6 & 1,7 & 58 & 16,9 \\
\hline TK ngoại vi & 91 & 26,6 & 12 & 3,5 & 0 & 0 & 103 & 30,1 \\
\hline
\end{tabular}

Nhận xét: Hầu hết bệnh nhân gặp độc tính chung trên lâm sàng độ 1 . Nhưng có $3,2 \%$ số đợt nôn mức độ 3- 4; 2,6\% bệnh nhân chán ăn mức độ 3-4; 1,5\% tiêu chảy mức độ 3-4; 1,7\% hội chứng bàn tay chân độ 3-4,

\section{BÀN LUÂN}

Đăc điểm của bênh nhân. Trong thời gian nghiên cứu, có 57 bệnh nhân ung thư dạ dày được phẫu thuật triệt căn kết hợp điều trị hóa chất phác đồ EOX. Tuổi trung bình là $63,7 \pm 3,4$ tuổi, thấp nhất là 60 tuổi, cao nhất là 72 tuổi (bảng 3.1). Bệnh kèm theo chủ yếu là tăng huyết áp $(15,8 \%)$, viêm loét dạ dày $(12,3 \%)$, bệnh thận hoặc đường tiết niệu $(12,3 \%)$, đái tháo đường $(10,5 \%)$.

Kết quả này cao hơn so với các tác giả trong nước như: Đỗ Trọng Quyết là 58,2 [4], của Vũ Quang Toàn là 53,4 [5]. So sánh giữa nhóm dưới 65 tuổi và trên 65 tuổi, phân bố độ tuổi tương đồng giữa 2 giới nam và nữ, sự khác biệt không có ý nghĩa thống kê với $p>0,05$. Tuy nhiên, số lượng nam là 43 bệnh nhân, gấp 3 lần nữ 14 bệnh nhân, tỉ lệ xấp xỉ 3/1. Kết quả này cao hơn nhiều so với các nghiên cứu của Đỗ Trọng Quyết [4] là $2,5 \ldots$... Sự khác biệt này có thể được giải thích rằng, nghiên cứu chúng tôi thực hiện đối với người cao tuổi, trong khi đó các tác giả khác thì thực hiện trên toàn bộ các nhóm tuổi.

\section{Một số độc tính và tác dụng không} mong muốn của phác đồ

Về liều thuốc. Tất cả bệnh nhân được điều trị với liều $85-100 \%$ trong 6 chu kỳ, trong đó có $28,7 \%$ số chu kỳ dùng đủ $100 \%$ liều. Ở chu kỳ 1 có tỷ lệ bệnh nhân điêuu trị liều tối đa thấp nhất do hâu hết các bệnh nhân sau phẫu thuật cắt dạ dày còn chưa hồi phục khả năng dinh dưỡng nên đánh giá dung nạp khó có thể dung liều tối đa. Trong quá trình điều trị, nếu xuất hiện độc tính trong khả năng bệnh nhân còn có thể theo được liêu trình điều trị sẽ điều chỉnh liều hóa chất. Chính vì vậy, ở những chu kỳ 5 và 6 có tỷ lệ bệnh nhân đang được dùng liêu tối đa đã giảm xuống liều trong giới hạn $85 \%$ - $<100 \%$.

Về tác dụng không mong muốn. Hóa trị độc tế bào là phương pháp sử dụng các tác nhân gầy độc tế bào, tác động vào quá trình phân chia của tể bào với mục đích điều trị toàn thân, tiêu diệt các tế bào ung thư. Do đó, ngoài tác đônng lên tế bào ác tính thì chúng cũng gây ảnh hưởng đến tế bào lành. Khi sử dụng trong điều trị ung thư, các thuốc đã được tính toán dùng với liều tác đông tới tế bào ung thư là tối đa trong khi tác động đối với tế bào lành ở mức chấp nhận được.
Thường các tế bào lành ở các cơ quan có nhiều tế bào non hoắc mức đô sinh sản nhân đôi cao chịu ảnh hưởng sớm nhẩt trong đó hay gặp ở hệ tao huyết và biểu mô đường tiêu hoá. Đônng thời, do thuốc chuyển hoá và đào thải chủ yếu qua gan, thận nên cũng gây ảnh hưởng tới chức năng của hai cơ quan này. Hầu hết bệnh nhân gặp tác dụng không mong muốn chung trên huyết học độ 1 với huyết sắc tố chiếm tỉ lệ cao nhất là 28,9\%. Đặng Hoàng An (2015) điểu trị bổ trợ bằng hóa - xa trị đồng thời và hóa trị EOX tại Huế chủ yếu thiểu máu ở độ 1 với 40,5\% [6]. Đáng chú ý có $1,5 \%$ hạ bạch cầu, 2,6\% hạ bạch cầu hat độ $3-4$ và $0,4 \%$ hạ tiểu cầu độ 4

Tác dụng không mong muốn đối với chức năng gan, thận chủ yếu biểu hiện trên các xét nghiệm men gan (GOT, GPT) và xét nghiệm chức năng lọc của thận (Ure, Creatinin). Hầu hết bênh nhân găp tác dụng không mong muốn chung trên chức năng gan-thận độ 1-2 với SGOT $29,3 \%$, SGPT $20,2 \%$, creatinin $5,8 \%$, ure $3,8 \%$. Do chuyển hóa của các thuốc trong phác đồ khi qua thận ở dạng không còn hoạt tính (ngoại trừ Oxaliplatin) nên mức độ ảnh hưởng lên chức năng đào thải của thận là rất thấp. Tác dụng không mong muốn trên thận ít gặp và chỉ ở mức độ nhẹ, không có trường hợp nào xuất hiện độc tính nặng.

Biểu hiện buồn nôn và nôn là những tác dụng phụ thường găp trong hóa tri. Trong phác đồ có sử dung Epirubicin là thuốc gây nôn manh nên tỷ lệ gặp cao. Tính chung qua 6 chu kỳ các bệnh nhân gặp tỷ lệ biểu hiện buồn nôn và nôn chủ yếu ở mức độ nhe và vừa, có $3,2 \%$ số đợt nôn mức độ 3- 4. Bệnh nhân chán ăn gặp ở 44,4\% và mức độ 3-4 gặp 2,6\%

Tiêu chảy là một trong số những tác dụng không mong muốn thường gặp khi điều trị hóa chất phác đồ có Capecitabine. Các bênh nhân trong nhóm nghiên cứu sử dụng Capecitabine trong phác đồ với liều vừa phải nhưng kéo dài nên cũng gặp tác dụng này, tuy nhiên chỉ gặp ở $17,5 \%$ trường hợp, trong đó có 1,5\% tiêu chảy mức độ 3-4.

Hội chứng bàn tay - chân là một trong những tác dụng không mong muốn đặc trưng và thường găp khi điều trị phác đồ có chứa Capecitabine. Qua 6 chu kỳ biểu hiện gặp ở 
16,9\% số trường hợp và chủ yếu ở độ 1,2 . Xuất hiện tăng lên ở những chu kỳ sau và có $1,7 \%$ độ 3-4, phải giảm liều thuốc Capecitabine $25 \%$.

Tác dụng không mong muốn trên thần kinh ngoại vi là biểu hiện thường gặp liên quan tới liều điều trị Oxaliplatin. Bao gồm độc tính cấp xuất hiện ngay trong hoặc sau quá trình truyền thuốc. Tính chung cả 6 chu kỳ hóa chất gặp $30,1 \%$ các trường hợp và thường tăng lên ở những chu kỳ cuối. Chủ yếu ở mức độ 1,2 với dấu hiệu dị cảm nhẹ, tê đâu chi, không ảnh hưởng đến điều trị

Có 05 bệnh nhân dung nạp thuốc kém phải chuyển sang phác đồ xelox do dung nạp thuốc kém.

\section{KẾT LUÂN}

Tác dụng không mong muốn chung trên huyết học chủ yếu ở độ 1 , trong đó có $1,5 \%$ hạ bạch cầu, 2,6\% hạ bạch câu hạt độ 3 - 4 và $0,4 \%$ hạ tiểu cầu độ 4

Tác dụng không mong muốn chung trên chức năng gan thận chủ yếu ở độ $1-2$, trong đó cao nhất là tăng SGOT $(29,3 \%)$ và SGPT $(20,2 \%)$

Tác dụng không mong muốn chung trên lâm sàng chủ yếu ở độ 1 , trong đó có có $3,2 \%$ số đợt nôn mức độ 3- 4, 1,5\% tiêu chảy mức độ 3-
4. Bệnh nhân chán ăn mức độ 3-4 gặp 2,6\% .

Có 05 bệnh nhân dung nạp kém phải chuyển phác đồ Xelox do dung nạp thuốc kém

\section{TÀI LIẸU THAM KHẢO}

1. World Health Organization (2018). Gastric Cancer. International Agency for Research on Cancer, GLOBOCAN 2018.

2. Vũ Hải (2009), Nghiên cứu chỉ định các phương pháp phâu thuật, hoá chất bố trợ và đánh giá kết quả điêu trị ung thư dạ dày tại Bệnh viện K, Luận án Tiến sĩ y học, Hoc viện Quần y.

3. Phan Cảnh Duy (2019), "Kết quả điều trị ung thư biểu mô tuyến dạ dây phần xa da dày giai đoan tiến triển tai chố bằng phẫu thuât kết hợp xa - hóa sau mổ", Tạp chí Y học lâm sàng, Bệnh viện Trung Ương Huể, số 55 , tr. $80-88$.

4. Đố Trọng Quyết (2010), Nghiên cứu điều trị ung thư dạ dày bằng phẫu thuật có kết hợp ELF và miển dịch trị liệu ASLEM, Luận án Tiến sĩ y học, Đai học Y Hà Nối.

5. Vữ Quang Toản, Đoàn Hữu Nghi, Đỗ Anh Tú (2015) , "Điều trị ung thư da dày tiển triển tại chổ bằng phẫu thuật và hóa trị bổ trợ EOX", Tạp chí Y học lâm sàng, số 29/2015, trt.270-278.

6. Đă̆ng Hoàng An, Nguyê̂n Thanh Ái, Pham Như Hiệp và cs (2015). "Đánh giá kết quả điêu trị bổ trợ ung thư da dày giai đoạn II-III bằng xạ trị và hóa trị với phác đồ EOX tại Bênh viên Trung ương Huế". Tạp chí y học lâm sàng, số 29, tr.258-269.

\section{NGHIÊN CỨU YẾU TỐ TIÊN LƯỢ'NG TỬ VONG Ở BỆNH NHÂN NGộ ĐộC CẤP METHANOL}

\section{TÓM TẮT}

Mục tiêu: Đánh giá các yễu tố lâm sàng, cận lâm sàng và điều trị liên quan đến tử vong ở bệnh nhân ngộ độc cấp methanol. Đối tượng và phương pháp: Nghiên cứu mô tả trên 107 bệnh nhân ngộ độc cấp methanol điêu trị tại Trung tâm chống độc bệnh viện Bạch Mai từ 01/2016 đến 07/2019. Kết quả: Bệnh nhân chủ yếu là nam giới $(97,2 \%)$; tuổi trung bình là 47,6 $\pm 12,6$ năm và nhóm tuối 40-59 găp nhiều nhất $(65,4 \%)$. Ngộ độc methanol thường nặng, tỉ lệ tử vong cao $(41,1 \%)$. Một số yếu tố liên quan đến tử vong ở bệnh nhân ngộ độc cấp methanol: đến viện muộn sau ngộ độc quá 24 giờ (OR 1,$04 ; p<0,05)$; hổn mê sâu (OR 0,24; $p<0,05)$; toan chuyển hóa nặng pH $<7,0$ (OR 0,22; $p<0,05$; Suy thận cấp (OR 5,13;

\footnotetext{
${ }^{1}$ Trung Tâm Chống Độc - Bệnh viện Bạch Mai

${ }^{2}$ Trường Đại học Y Hà Nội

Chịu trách nhiệm chính: Đặng Thị Xuân

Email: xuandangthi@bachmai.edu.vn

Ngày nhận bài: 01.3.2021

Ngày phản biện khoa học: 27.4.2021

Ngày duyệt bài: 10.5.2021
}

\section{Đặng Thị Xuân ${ }^{1}$, Hà Trần Hưng ${ }^{1,2}$}

$p<0,05)$; tăng glucose máu (OR 13,28; $p<0,05$ ); tụt huyết áp phải dùng thuốc vận mạch (OR 0,019; $\mathrm{p}<0,01)$. Kết luận: Nghiên cứu cho thấy sự liên quan giữa một số đặc điểm về lâm sàng, cận lâm sàng và điều trị với tử vong ở bệnh nhân ngộ độc cấp methanol. lượng.

Tư khóa: ngộ độc methanol, tử vong, yếu tố tiên

\section{SUMMARY \\ RESEARCH OF FACTORS RELATED TO MORTALITY IN PATIENTS WITH METHANOL POISONING}

Objective: to evaluate the factors related to fatal outcome in the patients with acute methanol poisoning. Subjects and Methods: A analysis observational study included 107 patients with methanol intoxication treated at Poison Control Center of Bach Mai Hospital from January 2016 to July 2019. Results: The study patients were mainly male $(97.2 \%)$, the mean age were $47.6 \pm 12.6$ years and mainly in the age group of 40-59 (65.4\%). Methanol poisoning is severe with high mortality rate $(41.1 \%)$. Some main factors related to death in patients with acute methanol poisoning: delay admission (more 